\title{
O ROMPIMENTO DA BARRAGEM DE FUNDÃO EM MARIANA/MG E A PROTEÇÃO DOS DESLOCADOS AMBIENTAIS: UMA ANÁLISE POR MEIO DE PESQUISA DE CAMPO
}

\section{THE RUPTURE OF THE FUNDÃO DAM IN MARIANA (MINAS GERAIS - BRAZIL) AND THE PROTECTION OF ENVIRONMENTAL DISPLACEMENT: AN ANALYSIS BY FIELD RESEARCH}

\section{LEONARDO DA ROCHA DE SOUZA}

Pós-doutor em Direito (UFRGS). Doutor e Mestre em Direito (UFRGS). Bacharel em Direito (UNISINOS). Professor Efetivo da Universidade Regional de Blumenau/SC (FURB). Advogado. E-mail: leonardorocha@furb.br

CAROLINA PAAZ Mestre em Direito pela Universidade de Caxias do Sul/RS (UCS). Especialista em Perícia e Auditoria Ambiental e Bacharel em Direito (Universidade de Rio Verde/GO). Advogada. E-mail: carolina.paaz@rdctv.com.br

\section{RESUMO}

Este texto aborda uma das maiores tragédias ambientais da história do Brasil, o rompimento da barragem da Samarco em Mariana/MG, sob a ótica dos deslocamentos ambientais, tendo elementos conceituais e técnicos para abordar o problema. Procura-se analisar os conceitos polêmicos dos termos utilizados que designam pessoas atingidas por desastres ambientais, a falta de terminologia adequada para os deslocados ambientais, bem como analisar quais são os instrumentos que garantem os direitos básicos dessa população deslocada. Para isso, sob olhar epistemológico hermenêutico-dialético, utiliza-se o método do estudo de caso com a técnica da pesquisa de campo realizada com pessoas atingidas pelo 
rompimento da barragem, tendo com linha condutora um roteiro com questões abertas.

PALAVRAS-CHAVE: Desastre ambiental; Deslocados ambientais; Barragem de Fundão; Mariana/MG; Democracia deliberativa.

\section{ABSTRACT}

This text addresses one of the greatest environmental tragedies in Brazilian history, the rupture of the Samarco dam in Mariana / MG, from the point of view of environmental dislocations, with conceptual and technical elements to address the problem. It seeks to analyze the controversial concepts of terms used to describe people affected by environmental disasters, the lack of adequate terminology for environmental displaced persons, and to analyze which are the instruments that guarantee the basic rights of this displaced population. For this, under the hermeneutic-dialectic epistemological approach, the case study method is used with the field research technique performed with people affected by the rupture of the dam, with a line with a script with open questions.

KEYWORDS: Environmental disaster; Environmental Displacement; Fundão dam; Mariana/MG; Deliberative democracy.

\section{INTRODUÇÃO}

$O$ ano de 2019 iniciou com um desastre ambiental cujas consequências ainda estão sendo calculadas: o rompimento da barragem de rejeitos de minérios da Vale S.A. (doravante Vale) em Brumadinho/MG. Essa mesma empresa é uma das controladoras da empresa Samarco Mineração S.A. (doravante Samarco), responsável pela barragem de Fundão em Mariana/MG, que rompeu em 05 de novembro de 2015. Em ambos os casos, rejeitos de minérios se deslocaram 
causando mortes de pessoas, de animais e da vegetação, além de causarem inúmeras outras consequências.

O objetivo deste artigo é estudar o rompimento ocorrido em 2015 que, se fosse melhor considerado e avaliado, teria prevenido o rompimento de 2019. Foi realizada uma pesquisa de campo durante uma semana do mês de setembro de 2016, na cidade de Mariana/MG. Foram entrevistadas 15 pessoas, sendo 8 deslocados ambientais, 1 Coordenador do SINE, 2 Assistentes Sociais, 1 Promotor de Justiça e 2 moradores da cidade. Os dados coletados apontam para surpreendentes problemas ocasionados não só para os que foram atingidos diretamente, mas também para os atingidos indiretos.

Foram utilizados termos de consentimento livre e esclarecido (TCLE) para os entrevistados para informa-los da realização, justificativa, procedimentos e objetivos da pesquisa, bem como obter permissão para a realização do estudo. Antes da coleta de dados, foi explicado ao entrevistado que ele deveria assinar o Termo de Consentimento Livre e Esclarecido (TCLE), de acordo com a Resolução 466/12 do Conselho Nacional de Saúde, em duas vias. Uma ficou em posse do sujeito e a outra com a pesquisadora.

As entrevistas realizadas com os atingidos e demais membros da comunidade de Mariana/MG se deu com o intuito de descobrir as consequências sociais, econômicas e ambientais após o desastre ambiental, bem como averiguar a forma de participação das comunidades atingidas nas deliberações ambientais, antes e após o desastre, analisando a complexidade que envolvem esses temas abordados.

O plano de análise dos dados dessas entrevistas se deu através da Análise de Conteúdo, considerando as características do modo que foi feita a entrevista. As respostas dos participantes foram deslocadas dos protocolos individuais para um protocolo geral e foram agrupadas em torno da pergunta que deu origem à resposta. Essa pesquisa de campo gerou material para alguns artigos. $O$ recorte dado para 0 presente texto selecionará as respostas relacionadas ao deslocamento ambiental, o que será realizado no tópico 3. Antes disso, no tópico 2, realiza-se uma revisão teórica a respeito da proteção dos deslocados ambientais, com ênfase para aqueles que se deslocam em virtude de desastres ambientais. 


\section{A PROTEÇÃO DOS DESLOCADOS AMBIENTAIS}

Pela sua própria essência, o homem não nasceu para viver isolado. Por isso, sempre procurou um lugar para morar, onde pudesse se abrigar e viver em grupo. (SOUZA, 2019). Segundo Harari (2017, p. 12), durante cerca de 2,5 milhões de anos os animais se alimentaram com as plantas dos locais em que viviam e caçando animais selvagens. Porém, cerca de dez mil anos atrás, os sapiens começaram a manipular a vida de algumas espécies de plantas e de animais. Os humanos começaram a espalhar sementes, conduzir ovelhas para pastos escolhidos, ocorrendo assim uma revolução na maneira como os humanos viviam, chamada de Revolução Agrícola. Nos lugares onde o trigo, a caça e outras fontes de alimentos se tornava abundantes, os bandos humanos puderam, pouco a pouco, abandonar seu estilo de vida nômade e se assentar em acampamentos onde se estabeleciam por uma estação inteira, ou mesmo permanentemente (HARARI, 2017, p. 87).

O homem da atualidade continua migrando por diversos fatores, dentre eles os econômicos, políticos, culturais e ambientais. Sob qualquer aspecto que envolva as sociedades humanas, percebe-se que a mobilidade humana sempre caracterizou a vida dos humanos. Porém, devido ao fato de grandes devastações e tragédias ambientais provocadas pelo homem, cada vez vai aumentar mais o número de pessoas que terão que sair compulsoriamente das suas casas por tragédias ambientais.

As questões ambientais vêm refletindo de forma expressiva nas condições de sobrevivência dos seres humanos provocando o deslocamento de populações, como ocorreu após a destruição atômica em Hiroshima e Nagasaki, no Japão, em 1945, a explosão de um reator na usina de Chernobyl, na Ucrânia, em 1986, derramamentos de óleo no mar do Alasca, em 1989, vazamento de gases tóxicos em Bhopal, na Índia, em 1984, considerado o pior acidente químico da história entre outros. No Brasil, houve o acidente causado pela contaminação propagada pelo material radioativo Césio 137 em Goiânia (GO), em setembro de 1987. Em novembro de 2011 foi a vez de o petróleo causar estragos ambientais sérios na Bacia de Campos, na região Norte do estado do Rio de Janeiro. Os mais recentes foram os desastre ocorridos no município de Mariana (2015) e Brumadinho (2019), 
ambos em Minas Gerais. Esses trágicos desastres ambientais citados, entre outros tantos, foram provocados pela mão do homem (GONÇALVES, 2017).

\begin{abstract}
Essa concepção de dominação humana - a visão de que os recursos ambientais estão disponíveis em função dos seres humanos - representou a maneira como o homem entendeu e percebeu a natureza, foi o paradigma orientador durante milênios, especialmente no Ocidente, e ainda está presente no mundo contemporâneo. Uma concepção que, além de insustentável, pode fazer a humanidade caminhar rumo ao ecocídio (TEIXEIRA, 2013, p. 25).
\end{abstract}

Existem, ainda, inúmeras dificuldades e implicações causadas em situações de deslocamento compulsório por tragédias ambientais (como o que a ocorreu após a tragédia da Barragem de Fundão) ou por deslocamento por mudanças climáticas por existirem muitas tipologias referentes ao mesmo assunto, tanto é que a própria Organização Internacional da Migração (IOM) do Programa de Nações Unidas para - Meio Ambiente (PNUMA) e o Painel Intergovernamental sobre Mudanças Climáticas (IPCC) têm demonstrado interesse no conceito, patrocinando inúmeras iniciativas (RAMOS, 2011, p. 44).

Percebe-se que, segundo dados mundiais, a tendência é que surjam cada vez mais deslocados ambientais em razão de mudança em seu ambiente natural, seja por desastres ambientais como aconteceu em Mariana, seja por causas naturais como secas, inundações, tempestades... fazendo com que ocorram grandes transformações tanto de ordem ambiental, quanto econômicos, sociais ou culturais (RAMOS, 2011, p. 42).

Os problemas do deslocamento ambiental devido a desastres no meio ambiente, apesar de envolver inúmeras circunstâncias, estão sendo relegados a segundo plano, à espera de uma terminologia mais adequada. Segundo a Agência da ONU para refugiados (ACNUR), o termo migração é comumente compreendido como um processo voluntário e que não pode ser utilizado como sinônimo de refugiado, pois há uma diferença legal crucial entre os dois. Enquanto os refugiados são pessoas que estão fora de seus países de origem por temores de perseguição política e/ou religiosa, por violências ou outras circunstâncias que perturbam a ordem pública e, por isso, precisam de proteção internacional, pois as circunstâncias frequentemente são extremamente perigosas para o retorno aos seus países de 
origem e potencialmente fatais para as suas vidas (ORGANIZAÇÃO DAS NAÇÕES UNIDAS, 2016).

Para a ONU, os refugiados têm um refúgio institucionalizado que thes garante proteção internacional, reconhecida no art. 14 da Declaração dos Direitos Humanos, que afirma o direito de toda e qualquer pessoa de buscar refúgio. A Convenção da ONU, de 1951, aprovou o Estatuto dos Refugiados, dando proteção e tratamento aos refugiados, com padrão internacional, incorporando valores humanitários fundamentais, sendo considerado um marco da humanidade (ORGANIZAÇÃO DAS NAÇÕES UNIDAS, 1951).

Segundo a ONU, os fatores que levam os indivíduos a migrar são complexos e envolvem causas multifacetadas:

\footnotetext{
Migrantes podem deslocar-se para melhorar suas condições de vida por meio de melhores empregos ou, em alguns casos, por educação, reuniões familiares, ou outras razões. Eles também podem migrar para aliviar dificuldades significativas ocasionadas por desastres naturais, pela fome ou de extrema pobreza. (ORGANIZAÇÃO DAS NAÇÕES UNIDAS, 2016).
}

Segundo Lopez (2007), a Convenção Relativa ao Estatuto dos Refugiados não foi redigida tendo em mente as pessoas deslocadas do ponto de vista ambiental, nem pode ser razoavelmente interpretada como incluindo essas pessoas, isso porque o termo refugiado é usado para definir quem tem temor de perseguição e nos casos dos deslocados ambientais não há perseguição nem política nem religiosa - não há perseguição do Estado - ao contrário, as vítimas de perseguição que fogem de desastre ambiental podem, na maioria dos casos, solicitar apoio para o seu próprio governo.

Não é possível encontrar proteção jurídica para os migrantes ambientais dentro do Estatuto dos Refugiados, tampouco se usa o termo refugiado ambiental para pessoas que são obrigadas a deixarem as suas casas por desastre ambiental. Existe, entre diversos estudiosos uma lacuna para definir o grupo dos migrantes ambientais bem como uma dificuldade para regulamentar essa forma de migração (SCALCO, 2014).

Conforme Oucho (2007, p. 6), as pessoas deslocadas por causas ambientais são conhecidos como refugiados e pessoas internamente deslocadas (Internally 
displaced persons - IDPs). Mattar, com base em Biermann e Boas, identifica os fatores característicos dos migrantes ambientais:

[...] são incapazes de retornar às suas casas; são suscetíveis de migrar em grandes números e coletivamente; são previsíveis, uma vez que a necessidade de se deslocar como resultado de impactos ambientais em determinadas áreas é evidente; e têm o direito moral de assistência em relação aos países industrializados, historicamente emissores de gases de efeito estufa. (MATTAR, 2012, p. 28).

Segundo Jubilut (2007, p. 169), o termo refugiado ambiental foi usado em 1985 pela primeira vez, mas, após a desertificação acentuada da África, o tsunami na Ásia, o terremoto no Paquistão e o furacão Katrina nos Estados Unidos, ouve uma pressão mais intensa para que essas pessoas fossem protegidas pelo sistema do Direito Internacional dos Refugiados. A autora cita, ainda, as causas principais dos refúgios ambientais com base em Karla Hatrick: "degradação da terra agriculturável, desastres ambientais, destruição de ambientes pela guerra, deslocamento involuntário na forma de reassentamento e mudanças climáticas". O enquadramento legal dessas pessoas como refugiados pode ser difícil, porém, essa deve ser a pauta das discussões internacionais, tendo em vista que, segundo a ONU, até 2050 existirão cerca de 150 milhões de pessoas na condição de refugiados ambientais (JUBILUT, 2007, p. 169-170).

Nos cenários mais extremos, os deslocados ambientais encontram-se em situações consideradas, de certa forma, mais desesperadoras do que as enfrentadas pelos refugiados, uma vez que a possibilidade de retorno pode ser mínima ou inexistente e torna-se urgente definir as reais necessidades dessas pessoas em relação à proteção de seus direitos fundamentais (MATTAR, 2012, p. 89).

[...] assim como no caso dos migrantes ambientais, não existe uma agência voltada especificamente à proteção dos deslocados internos. Considerando essa lacuna institucional, a Assembleia Geral da ONU solicitou, em 2005, ao Inter-Agency Standing Committee que elaborasse uma estratégia para a proteção dos deslocados internos. Como resposta a essa solicitação, o IASC estabeleceu uma abordagem conjunta de agências que o compõem distribuindo as competências quanto à proteção e assistência aos deslocados internos conforme a área de atuação de cada órgão. Ao ACNUR, foi atribuída a responsabilidade de proteção aos deslocados internos, apesar dessa categoria não estar inicialmente nas atribuições dessa agência. Por permanecerem cidadãos ou residentes de seus próprios países, os deslocados ambientais são protegidos por todas as garantias de 


\begin{abstract}
direitos humanos vinculantes ao Estado em questão, disponíveis para a população em geral. Todavia, é "ainda duvidosa a capacidade dos Estados mais afetados pelas alterações ambientais de garantir tal proteção e implementar os Princípios Orientadores Relativos aos Deslocados Internos, sobretudo aqueles com governança e estruturas da sociedade civil fracas e/ou onde não há interesse político para implementá-los" (MATTAR, 2012, p. 40-41).
\end{abstract}

Tanto a migração permanente quanto a temporária são uma estratégia de sobrevivência das pessoas que se veem confrontadas com algum impacto e com as consequências dos desastres ambientais e elas muitas vezes exacerbam a vulnerabilidade de populações inteiras, intensificando os seus impactos. Os deslocamentos são forçados e inevitáveis por não haver quaisquer condições de sobrevivência no local atingido (SPAREMBERGER; VERGANI, 2010, p. 130).

Segundo Bühring (2015, p. 206-207), um artigo escrito pelo professor egípcio Essam El-Hinnawi para o Programa das Nações Unidas para o Meio Ambiente (PNUMA), no ano 1985, foi o responsável por popularizar o termo "refugiados ambientais". Essa expressão veio a ser definida por Janos Bogardi como "aquelas pessoas que foram forçadas a abandonar o seu habitat tradicional, de forma temporária ou permanente, por causa de uma evidente perturbação ambiental [...], que ameaça a sua existência e/ou afeta gravemente a qualidade da sua vida.

Embora haja tantas pessoas deslocadas por eventos ambientais, percebe-se que elas pouco recebem reconhecimento formal na lei ou política internacional já que para nomeá-las existem uma diversidade terminológica. Porém, o grande cerne da questão é saber até que ponto as pessoas que são desarraigadas por uma catástrofe ambiental - temporariamente ou permanentemente - terão que ter assistência, que tipo de assistência e qual a proteção que elas devem receber. Ainda, discute-se se a proteção dada pelo regime internacional dos refugiados deveria ser dada para os refugiados ambientais.

Pelos indicadores o aquecimento global é uma realidade que está subindo a uma velocidade incrível e, infelizmente, os deslocamentos por motivos ambientais, até em zonas que não são endêmicas em catástrofes naturais, só irá aumentar, o que vai demandar que os países estejam prontos para poder atender às necessidades dessas pessoas, que são iguais às que fogem da guerra. 
Exemplo disso, é o caso dos haitianos que vêm chegando "ao Brasil desde 2010, após o terremoto que abalou o Haiti". No Brasil, existe a "possibilidade de proteger essas pessoas que [...] não se enquadram no conceito de refugiado da Convenção de 1951" (SOARES, 2016, p. 97). Isso se dá

[...] por meio da concessão de um visto de residência por questões humanitárias. Essa possibilidade surgiu através da Resolução Recomendada $\mathrm{n}^{\circ}$ 8, do Conselho Nacional de Imigração (CNIg), de dezembro de 2006, que foi acatada pelo CONARE [Comitê Nacional para os Refugiados], em março de 2007. (SOARES, 2016, p. 97).

A concessão de visto de permanência por questões humanitárias não é uma obrigação internacional, depende da vontade dos Estados. Mesmo assim, o Brasil concordou com a concessão de vistos aos haitianos atendendo à solicitação da ONU, que pediu aos governos que não deportassem os haitianos (SOARES, 2016, p. 98).

O problema em não se ter uma única terminologia para os casos de pessoas que são obrigadas a se deslocarem por motivos ambientais, interfere também nos cálculos dos números de migrantes climáticos/ refugiados/ atingidos. Isso também afeta a proteção jurídica dos deslocados ambientais, que constitui um desafio político muito importante pois existem complexos e multivariados processos (ambientais, políticos, sociais e econômicos) que envolvem esse problema.

Até pouco tempo atrás era usual falar que no Brasil estaríamos sempre salvos dos desastres ambientais. Porém, devido às transformações que o homem vem provocado no meio ambiente, cada vez mais se aumenta a exposição a enchentes, deslizamentos de terras e tantos outros problemas ambientais. Prova disso é o que se pode observar nos dados da Defesa Civil, que, no período de 1 ano, entre junho de 2016 e junho de 2017, registrou centenas de eventos. (BRASIL, 2017) Os desastres naturais no Brasil, tais como inundações, secas, ciclones e tufões, estão crescendo cada dia mais e não só produzem vítimas humanas e animais, mas também produzem a destruição do habitat natural e poluição.

Embora os desastres naturais ocorram em todos os lugares do mundo, seu impacto é muito mais relevante sobre as pessoas que vivem em um país como o Brasil e em outros países que enfrentam enormes desigualdades sociais. O impacto 
nesses lugares geralmente é calamitoso, pois não só danificam a terra como também prejudicam o cotidiano das pessoas afetadas, aumentando ainda mais a vulnerabilidade das pessoas atingidas. Um país desenvolvido geralmente está melhor preparado para lidar com o impacto das catástrofes. Nos países como o subdesenvolvidos, o que ocorre após um desastre, geralmente, é o aumento do ciclo de pobreza, pois os atingidos não têm os recursos para reconstruir as suas casas e satisfazer as necessidades básicas, tornando-as menos capazes de se recuperar a longo prazo. Como consequência maior, quando percebem que não vão conseguir se reerguer, muitos vão embora das suas terras, deixando tudo para trás, e migram em busca de uma vida digna.

A quantidade de desastres ambientais que vêm ocorrendo sugere que várias medidas de mitigação devem ser amplamente debatidas entre governos e instituições, com uma visão holística sobre o assunto, com políticas públicas de segurança humanitária, para que as tomadas de decisões sobre o futuro dos deslocados ambientais sejam realmente eficazes e tragam como resposta a forma de se garantir a proteção dos direitos humanos das vítimas desses desastres.

Parece que a preocupação humanitária tem ficado de lado. O que está em jogo são as políticas econômicas que envolvem a questão das migrações, tanto é que diversos países não querem usar a expressão 'refugiados ambientais' devido ao pedido de asilo para refúgios que até podem gerar problemas políticos e sociais. Existe uma complexidade de fatores que envolvem os movimentos populacionais por questões ambientais. Ignorar a existência dos migrantes ou deslocados ambientais porque não há um modo institucionalizado de tratá-los é colocar em segundo plano uma questão latente que diz respeito aos direitos humanos fundamentais.

No rompimento da barragem de Mariana/MG em 2015, percebe-se a preponderância dos interesses econômicos e a ausência de proteção efetiva dos deslocados ambientais. No próximo tópico, essa percepção é demonstrada por meio da análise do caso e das entrevistas realizadas com os atingidos. 


\section{OS DESLOCADOS AMBIENTAIS DE MARIANA/MG E O REASSSENTAMENTO}

O Distrito de Bento Rodrigues, local onde a barragem se rompeu, foi totalmente devastado. Bento Rodrigues é um subdistrito de Santa Rita Durão, localizado no município mineiro de Mariana. Até 2015 cerca de 600 habitantes viviam no local e existiam cerca de 200 imóveis ocupados. Além de Bento Rodrigues, Paracatu, Pedras, Ponte do Gama, Camargos e Campinas também foram atingidas. Dezenove pessoas foram identificadas como vítimas fatais da tragédia. 329 famílias passaram a ficar desabrigadas pela lama em Mariana e região e estão morando em casas alugadas pela Samarco; 1.265 desabrigados foram alocados em hotéis e pousadas da região; 1,5 mil hectares de vegetação destruídos pela lama entre Mariana e Linhares (ES); 1.249 pescadores estão cadastrados na área afetada pela lama em Minas Gerais e no Espírito Santo (MINAS GERAIS, 2015).

Em decisão prolatada pela $12^{\circ}$ Vara Federal de Minas Gerais, $n^{\circ} 0069758$ 61.2015.4.01.3400, nos autos da ação que trata sobre o rompimento da barragem de Fundão e de Santarém, no Complexo Minerário de Germano, em Mariana/MG, segundo relatórios preliminares do IBAMA, a tragédia foi assim descrita:

Consta que, dos $50 \mathrm{~m}^{3}$ de rejeitos da mineração de ferro, $34 \mathrm{~m}^{3}$ de lama vazaram com o rompimento da barragem do Fundão, atingiram a barragem de Santarém logo a jusante, causando alagamento e formando onda de lama que atingiu a localidade de Bento Rodrigues, causando destruição e morte. Após passar pelo povoado, a onda de lama percorreu os rios Gualaxo e Carmo, entrando no curso do Rio Doce e percorrendo cerca de $600 \mathrm{Km}$ até a sua foz. Registra-se, ainda, que essa onda de lama, pelo caminho, destruiu comunidades, estruturas urbanas, áreas de preservação permanente, alterou profundamente a qualidade da água, com necessidade de interrupção do abastecimento de água para a população de alguns municípios e para atividades econômicas que dependem de sua captação no Rio Doce e exterminou a biodiversidade aquática e indivíduos de fauna silvestre. Esses elementos, ainda que não sejam suficientes para a identificação de danos causados, de natureza ambiental e socioeconômica, que inclusive ainda estão em expansão e envolvem processos dinâmicos, com impactos secundários de difícil previsão, são suficientes para comprovar cabalmente a existência de dano ao meio ambiente de enorme proporção, com impacto sobre vários aspectos e elementos que compõe a biodiversidade no estado de Minas Gerais e no estado do Espírito Santo.(BRASIL, 2015a). 
Os números demostram que, além da tragédia humana, o desastre em Mariana teve impacto ambiental ainda difícil de avaliar, segundo o Termo de Transação e de Ajustamento de Conduta relativo ao rompimento da Barragem de Fundão, em Mariana/MG:

\begin{abstract}
Os níveis de turbidez da água e dos sedimentos levaram à interrupção do abastecimento de água dos municípios e das atividades econômicas com captações nos rios atingidos. Além das vítimas fatais e dos feridos, ao longo do trecho afetado, foram constatados danos ambientais, econômicos e sociais diretos, tais como a destruição de moradias e de estruturas urbanas, destruição de áreas de preservação permanente, isolamento de comunidades, mortandade de animais de produção, impacto em plantações nas áreas rurais, restrições à pesca, danos à saúde, mortandade da fauna silvestre e doméstica, interrupção da geração de energia elétrica pelas hidrelétricas atingidas, suspensão do abastecimento de água e danos às áreas ambientalmente sensíveis. (BRASIL, 2016, p. 3).
\end{abstract}

A partir de uma análise primária e sistemática do citado documento infere-se que a tragédia de Mariana se configurou num desastre socioambiental, até então, de proporções nunca antes visto na história da mineração brasileira e mundial. Decerto, os efeitos dramáticos e perversos do "desastre de Mariana" serão sentidos por décadas e gerações, principalmente aquelas formadas por comunidades que estão localizadas dentro da bacia hidrográfica do Rio Doce.

O levantamento feito pelo professor de Geotécnica da Coppe- UFRJ (Centro de Pesquisa em Engenharia Ambiental), Maurício Ehrich, considerou que o resíduo da mineração que vazou é infértil, "porque não tem matéria orgânica", e nada mais nascerá no distrito de Bento Rodrigues. Para ele, "seria como plantar na areia da praia de Copacabana", e, portanto, nada mais se construirá nos lugares por onde a lama passou, porque é uma matéria mole "que não oferece resistência". Os lugares, segundo o engenheiro, se transformaram em "um deserto de lama", e o terreno afetado poderá levar até dezenas de anos para formar um novo solo (GERARQUE; MENA, 2015).

Considerando que não é mais possível que os moradores das comunidades atingidas voltem a residir nos locais que a lama destruiu, a Samarco, juntamente com a Comissão dos Atingidos, identificou três terrenos para reconstrução de Bento Rodrigues. Todos os terrenos ficam no Município de Mariana/MG. Após análise dos peritos contratados pela Samarco para verificar a compatibilidade para 0 
reassentamento, no dia 03.05.2016, houve apresentação dos terrenos e dados apresentados pela Samarco, ocasião que os atingidos tiveram a oportunidade de conhecer pessoalmente os terrenos. Houve direito a voto, por um representante, de cada unidade familiar, para escolha da nova Bento Rodrigues (MINAS GERAIS, 2015).

O Distrito onde será reconstruída a comunidade é uma área que foi escolhida por 206 votos (92\% do total), conhecida como Lavoura, de propriedade da empresa Arcelor Mittal. O terreno que deve abrigar o novo Bento Rodrigues fica a cerca de oito quilômetros da sede da cidade histórica e a cerca de nove quilômetros do distrito destruído pelo "mar de lama". Segundo autos do processo, a $2^{\circ}$ Promotoria de Justiça da Comarca de Mariana/MG, assim se manifestou sobre a escolha da nova localidade que vai abrigar os atingidos:

No dia 02 de março de 2016, entre 10h e 13h, equipe do Ministério Público de Minas Gerais (MPMG), composta por Promotor de Justiça e peritos do CAOET, fez inspeção no terreno onde pode ser reconstruída a comunidade de Bento Rodrigues, em Mariana/MG. Fizeram parte da diligência 0 Promotor de Justiça Guilherme de Sá Meneghin, os peritos Nadson (engenheiro civil) e Maria Luíza (arquiteta) do MPMG, moradores de Bento Rodrigues (especialmente os membros da comissão de moradores Antônio, conhecido como "Antônio Da Lua", "Zezinho do Bento" e "Zezinho Café"), o Secretário de Obras do Município de Mariana, técnicos do Serviço Autônomo de Água e Esgoto de Mariana e o Secretário de Meio Ambiente do Município de Mariana. Em uma análise preliminar, o terreno, conhecido como "Lavoura", mostra-se favorável à reconstrução de Bento Rodrigues. Fica a $12 \mathrm{~km}$ de distância da sede do Município de Mariana, possui declividade apropriada, terra fértil, mananciais para abastecimento da população e engloba, aproximadamente, 200 hectares. Registre-se que o antigo Bento Rodrigues, arrasado pelo rompimento da barragem de Fundão, da Samarco Mineração S/A, no dia 05 de novembro de 2015, tinha cerca de 200 edificações, distribuídas em 100 hectares. Desse modo, a proposta é que o terreno seja maior do que o antigo Bento Rodrigues, de maneira a contemplar a dinâmica de crescimento da comunidade. Serão realizadas várias perícias para verificar se o terreno possui, do ponto de vista técnico, as características necessárias para reconstrução da comunidade, inclusive se os mananciais identificados possuem vazão suficiente para abastecer a população a ser reassentada. Após, sendo a avaliação favorável, serão tomadas as medidas para submeter o terreno à aprovação dos atingidos e, posteriormente, serão encerrados os procedimentos para aquisição do local, atualmente de propriedade da Arcelor Mittal. (MINAS GERAIS, 2015).

Segundo o Promotor de Justiça, a proposta é reerguer um novo distrito, com uma certa semelhança com os distritos que foram destruídos: 


\begin{abstract}
Entrevista 16/17 (promotor de justiça): E qual é a proposta deles, é montar toda a estrutura de uma cidade, ou só a casa, praça? Não, vai reerguer toda vila com a Igreja, com Praça, com escola, com posto de saúde, tudo que tinha lá e mais um pouco, como compensação. Isso eles já concordaram? Está no processo. Eles, de certa forma, concordaram na medida em que eles compraram o terreno que foi escolhido pela população. Como é que foi: três terrenos foram escolhidos, a população foi convocada, os atingidos, a votarem e escolherem, eles votaram e escolheram. Você pode encontrar notícia sobre isso na Internet, você vai ver - população de Bento vota e escolhe terreno - então isso aí vocês vão conseguir.
\end{abstract}

Como em qualquer distrito ou cidade, as pessoas não moram em casas de tamanho padronizados, cada uma tem seu tamanho e sua característica. Para o Promotor de Justiça uma certa padronização das casas será necessária, porém, os tamanhos das residências devem ser diferentes, haja vista que nem todos os moradores moravam em casas do mesmo tamanho:

\begin{abstract}
Entrevista 16/17 (promotor de justiça): E a questão de tamanho de casa, por exemplo, eu tinha uma casa, e o meu vizinho tinha uma casa bem menor, e eu tinha uma casa bem maior, vão ser casas com padrões de tamanho? Olha, alguma padronização será necessária, mas aquela ideia de cinco casas padrões nós somos totalmente contrários, ela tem que refletir, primeiro, o terreno que a pessoa tem, tem que refletir o que ela tinha antes, então, nós vamos tentar fazer que seja similar ao que ele tinha antes, então, se ele tinha cem metros quadrados, que a casa dele tenha cem metros quadrados, disso ou mais; se a casa tinha cinquenta metros quadrados, que a tenha cinquenta metros quadrados ou mais, ela não pode ter menos. Agora, alguma padronização será necessária, por exemplo, a telha era tal, quer dizer, na questão de telha nós vamos ter que botar um padrão porque não dá para ficar escolhendo muito, agora, nós vamos tentar refletir o status quo deles.
\end{abstract}

Questionado sobre o hábito que a maioria dos moradores das comunidades atingidas tinha, de cuidar da terra e plantar seus alimentos, e de como será após a construção do novo distrito, o Promotor de Justiça assim esclarece:

Entrevista 16/17: eu vejo as pessoas mais idosas que eu conversei, elas falam muito da terra pra plantar, que elas tiravam os alimentos, que pra elas, elas não vinham pra cidade pra comprar verdura, fruta, então, o tamanho da área também vai representar, se eu tinha cinco hectares, será um imóvel de cinco hectares? Isso, esse é o pedido do processo, se isso vai acontecer no final ou não, a gente tá sempre entrando em acordos com empresa e a gente espera entrar num acordo sobre a reconstrução. Então, agora eles já adquiriram o terreno e isso está seguindo uma lógica aceitável. 
Os deslocados ambientais permaneceriam por três anos morando em casas alugadas pela Samarco, dentro da cidade de Mariana, para posteriormente irem para uma nova comunidade, completamente diferente dos distritos em que viviam. Além dos atingidos diretos, existem uma centena de comunidades locais que também foram atingidas pela poluição das águas e que terão que se deslocar a fim de garantir o sustento de suas famílias, que antes do desastre, retiravam os seus alimentos dos rios.

A reconstrução do distrito de Paracatu também contou com a participação de todos os atingidos:

VOTAÇÃO TERRENO PARA RECONSTRUÇÃO DE PARACATU. No dia 03 de setembro de 2016, entre 8h e 17h, no Centro de Convenções de Mariana, foi realizada a eleição para escolha do local onde será reconstruída a Comunidade de Paracatu, que foi destruída pelo desastre do dia 05-11-2015. Ao final da apuração se obteve como resultado: a) Terreno de Joel 01 voto; b) Terreno do Toninho 33 voto; c) Terreno de Lucila 67 votos; d) Brancos e nulos 02 votos. Todos os terrenos situam-se na zona rural de Mariana. Ao final da contagem dos votos, foi divulgado o resultado: o terreno de Lucila, com 67 votos, foi o escolhido pelos atingidos para reconstrução de Paracatu. O Ministério Público de Minas Gerais, através do oficial do MP Anizio Aparecido Santos, acompanhou toda a votação, que ocorreu sem qualquer problema. A reconstrução de Paracatu segue os mesmos parâmetros pactuados entre a comissão de atingidos, as empresas rés (Samarco, Vale e BHP) e o Ministério Público de Minas Gerais, na área que atua na defesa dos direitos humanos: $1^{\circ}$ ) seleção de três terrenos em conjunto com representantes da comunidade; $2^{\circ}$ ) estudos de viabilidade dos terrenos; $3^{\circ}$ ) escolha dos terrenos pelos atingidos, em votação fiscalizada pelo Ministério Público; 4ํ) projeto arquitetônico e executivo, que será o próximo passo, com participação dos atingidos e da assistência técnica conquistada para auxiliar as vítimas do evento; 4) execução das obras com fiscalização dos atingidos e do Ministério Público. (MINAS GERAIS, 2015).

Considerando as dimensões do desastre, os danos materiais e imateriais, o plano de reassentamento prevê a construção de casas padrões, com provisão de água potável e infraestrutura sanitária, com escola, igreja, praça, com o fim de restituir, em um prazo de dois anos, os distritos que foram destruídos. Até a conclusão deste artigo, em março de 2019, ainda não se tem notícia do cumprimento desse prazo, embora tenha sido registrado um avanço nessa reconstrução. Esse atraso tem levado o Ministério Público a cobrar, judicialmente, a aplicação de multa à Samarco (RODRIGUES, 2019). 
O depoimento da deslocada ambiental, ilustra a esperança que se tem de que a vida melhore após o reassentamento:

Entrevista 05 (deslocado ambiental) A gente ter certeza quando que eles vão começar (inaudível) ter certeza que a gente poder, eles falar assim - "a partir desse momento, tá pronto pra fazer o novo Bento", porque eles ficam enrolando, enrolando, como diz, que é votado pra escolher o lugar onde vai ser... até hoje não deram solução nenhuma, não falaram mais nada, quando vai começar, se vai ser lá mesmo... até hoje tá a instalação, a gente fica preocupada. E a instalação vai ficar aqui, mais ou menos, três anos. Vocês acreditam que vão poder ter uma vida como antes? A gente tem esperança, porque a última que morre é isso. Vai demorar um "bocadinho". Aí tem tanta gente que são assim - "nossa, será que vai acontecer isso mesmo?" A gente fica imaginando, eu fico imaginando assim - "será que eu vou tá viva até lá", a gente imagina assim, - "será que a gente vai tá pra conhecer o novo Bento...", "será que os pais da gente tudo vai pra lá?"

Em tom de desabafo de outro deslocado ambiental, resta evidente a insegurança de não saber se vai se adaptar em um outro local, bem como a angústia de ver a neta crescer em um novo lugar que não conta com os recursos naturais que Bento Rodrigues tinha, bem como o descontentamento de que a terra escolhida para o reassentamento é perto de um antigo lixão:

Entrevista 12 (deslocada ambiental) - Eles tão esperando só um negócio lá que vai liberar pra poder fazer o desmatamento, o terreno já tá comprado, já tá esperando a escritura pra fazer o desmatamento pra fazer a terraplanagem e fazer as casas. Só que tudo isso é demorado porque só pra escolher o terreno, a companhia mostrou acho que vinte terrenos, vinte e três terrenos, mostrou pra comunidade escolher, só que foi uma luta pra escolher esses terreno, porque lá nesse lugar que foi escolhido, eu vou pra lá porque eu tenho que ir, mas eu não queria ir pra lá, sabe, então tem pessoas que vão ter que morar lá, mas sem querer morar lá, porque lá tem um problema, tem um lixão, um aterro sanitário, acho que dois quilômetros ou não chega nem dois e diz que o aterro sanitário tem que ser mais distante, esse é o problema nosso, digamos...Sim, não vai ter a água que vocês tinham, é isso? A água nossa não tem como, ela vai ser tirada ou do Rio Gualaxo, que tem que ser tratada porque tem rede de esgoto dentro dela, então vai ser tratada, ou fazer poço artesiano, tirar a água do poço com bomba, então, eu creio que isso pra nós vai ser muito ruim, muito ruim mesmo, mas eu, principalmente, eu não culpo a Samarco, eu culpo a população porque foram 200 (duzentos) votos contra 15 (quinze) votos. Para escolher o local? Pra escolher o local, foi 200 (duzentos) votos contra 15 (quinze) votos. Porque o povo se apegou muito em Bento, porque o Bento, o povo é apegado ao Bento, então, o que eles fizeram, eles queriam o Bento, no caminho do Bento, virou aquele desespero - o Bento no caminho do Bento -, então escolheu esse lugar. Então foi esse o motivo da escolha. Eu já não escolheria, porque eu gostava do Bento, mas o Bento acabou, o que nós tinha lá, não tem, nós vamos pra um lugar agora que não tem córrego, tem corregozinho lá, a água do aterro cai nele, ele 
não é córrego, se você entrar dentro dele [...] O lugar que eu vou morar eu acho que não vou gostar... pode ser que quando a casa tiver pronta, eu vou gostar, é isso que eu fico pensando, às vezes, na hora que tiver pronta, que eu chegar lá, eu vou gostar, mas, nesse momento, não tem nada de perspectiva, é muito ruim, por causa de uma coisa que eu não sei se tá no papel ou se tá na "boca", porque no papel é mais... enquanto tá na "boca" não se sabe, coisa de "boca" você sai e pronto, acabou... É tirar o aterro sanitário de lá. Falaram em tirar, porque eu tava acelerando, porque quando eu lembro daquilo, do aterro sanitário ali, me dá uma tristeza de eu saber que eu vou ter que ir pra um lugar que tem um aterro sanitário, não é por mim, igual eu falo, pra muita gente eu já falar, não é por mim e pelo marido, não, porque eu e o meu marido, eu tô 58 anos, o meu marido 63 anos, nós já estamos indo, mas eu tenho uma netinha que vai fazer um aninho sábado, o pai dela falou que ele não vai pra lá, ele vai ter que dá um jeito, fazer alguma coisa. Sabe por que, esse menino aqui puxa na Internet, aí tem uma distância de mais de três quilômetros.

Esse difícil período de reconstrução, aliado à insegurança de saber se vai gostar ou não do local escolhido para o reassentamento, também está descrito na fala de outro deslocado ambiental, ao relatar o que espera após o reassentamento:

Entrevista 11/12 (deslocado ambiental): Agora tem, que eles fizeram, tem até o lugar. Só que ficou fora de Paracatu, bem fora, no caminho de Forquilha. É, ficou fora da onde que a gente morava. Ficou mais perto daqui do que Paracatu. É um novo Distrito? Isso. É o lugar que escolheram melhor, livre de rio, livre de falar assim - "ah, vem outra barragem e vai atingir", porque lá no Paracatu, só se eles cortassem um pouquinho de volta redonda lá na frente, mas é muito mato. Lá não tem como cortar por causa das matas que tem lá. Não pode construir lá. E mesmo a onde nós morava lá, não tem como, porque lá ficou super cheio de lama, onde que nós morava, a parte mais baixa, aí não tem como construir... Aí, no caso, dizem que o Estado vai fazer a mesma, que era o novo Paracatu, vai fazer igual era o antigo, vamos ver, eu acredito que não vai ser a mesma coisa, igual era, não sei. [...] Não aguento ficar sem fazer nada. Eu sou acostumada a me mexer, eu ficava braba demais de não ter o que fazer - eu vou fazer o que - tinha que ficar só parada, não tem como, uai.

As pessoas que foram vítimas do desastre, provocado pelo rompimento da barragem, e que foram forçadas a abandonar os seus locais por causa da perda completa e irreversível das suas casas, terão que se adaptar duas vezes a uma nova vida: uma atualmente, devido ao deslocamento para a cidade de Mariana e, posteriormente, para novos distritos. O reassentamento dessas famílias precisa ser em um lugar que não cause mais sofrimento ou mortalidade das pessoas deslocadas e isso só ocorrerá com significativos recursos financeiros 
disponibilizados para proporcionar-Ihes segurança e uma nova oportunidade de subsistência.

Durante a fase de reestruturação das vidas dos deslocados ambientais e dos atingidos indiretos, é imprescindível que haja, por parte do poder público, a fiscalização para que sejam respeitados os direitos humanos dos atingidos, com prestação de serviços assistenciais e restauração da moradia permanente, com um trabalho permanente voltado à redução das desigualdades sociais e da vulnerabilidade e, ainda, com muitas outras políticas públicas voltadas à redução dos danos das comunidades afetadas.

\section{CONCLUSÃO}

É imprescindível que se analise sob diversos aspectos a questão ecológica e a questão social, ambas decorrentes de um dos maiores desastres ambientais ocorridos no Brasil, no Estado de Minas Gerais, na barragem de rejeitos do Complexo minerário Vale/Samarco. Esse desastre, como mencionado acima, atingiu diversas cidades brasileiras, destruindo e contaminando com rejeitos da mineração uma extensa área e provocando os deslocamentos ambientais. A lama não só retirou vidas humanas e de animais, mas também enterrou sonhos e a dignidade das comunidades atingidas, deslocando de forma compulsória a todos e a tudo, tornando-os deslocados ambientais.

Faz- se necessário que o reassentamento em Mariana/MG tenha a participação ativa de todos os reassentados, com a maior rapidez possível, pois, quanto mais longo este reassentamento, maior o risco de geração de exclusão, pobreza e consequente degradação ambiental. Além disso, pode ocorrer com os deslocados ambientais que se encontram em Mariana uma divisão intergeracional, ou seja, na época do reassentamento definitivo, pode ser que muitos jovens não queiram sair da cidade de Mariana por já estarem adaptados.

A projeção, segundo dados mundiais, é que, a nível mundial, surjam cada vez mais deslocados ambientais em razão de mudança em seu ambiente natural, como secas, inundações e tempestades, ou por tragédias provocadas pelo homem, 
fazendo com que ocorram grandes transformações, tanto de ordem ambiental como econômicas, sociais e culturais.

O deslocamento ambiental proveniente de mudanças climáticas e outros desastres ambientais apresentam sérios desafios. A responsabilidade de proteção aos direitos humanos fundamentais dos deslocados não pode continuar sendo reduzida a meros conceitos enquanto milhares de pessoas sofrem por consequências causadas por problemas ambientais.

As causas de migração em massa ou deslocamentos ambientais contemporâneos têm de ser aprofundadas. Ademais, há a necessidade de encontrar a terminologia correta para os deslocados/ migrantes/refugiados ambientais, tendo em vista que a terminologia incorreta dá aos governos motivos para não criarem critérios e instrumentos de proteção adequados para salvaguardar os direitos das populações deslocadas por razões ambientais.

Urge a necessidade de mapear as zonas que precisam de maior atenção ambiental e monitorá-las, bem como montar um projeto de resiliência, de adaptação e preparação para tragédias ambientais envolvendo as populações locais - com o objetivo de mitigar os impactos ambientais e reduzir os conflitos sociais causados pelo deslocamento - evitando, assim, graves injustiças sociais.

Independente do reconhecimento de um estatuto internacional que proteja os deslocados ambientais, todas as questões que envolvem o deslocamento de populações devem ser amplamente debatidas. Tratam-se de pessoas que não têm outra alternativa senão buscar refúgios em outros lugares, devido à segurança ou a questões ambientais relacionadas ao solo, desertificação, desmatamento, ou devido à total devastação do local onde morava.

É imprescindível a adoção de programas de resiliência como pressuposto da construção de cidades sustentáveis e do desenvolvimento sustentável, conforme Declaração da Rio +20 , que recomendou que as cidades devem ser resilientes a fim de estarem preparadas para enfrentar os desastres ambientais. Para tanto, é necessário que os riscos sejam avaliados e que se promova a sustentabilidade das cidades, tornando-as resilientes. 


\section{REFERÊNCIAS}

BRASIL. Tribunal Regional Federal da $1^{\text {a }}$ Região. 12 $2^{\text {a }}$ Vara Federal de Belo Horizonte. Processo no 0069758-61.2015.4.01.3400. Classe: Ação Civil Pública. (2015a). Autor: União Federal e outros. Réu: Samarco Mineração S.A., Vale S.A., BHP Billiton Brasil Ltda. Data de Autuação: 17/12/2015, disponível em https://bit.ly/2uo7TFg, acesso em 21/03/2019.

Ministério do Desenvolvimento Regional. Defesa Civil aprimora assistência a regiões atingidas por desastres naturais: mudanças garantem mais agilidade a processos de trabalho, que agora também podem ser acompanhados pela sociedade. (2017). Publicação: 06/04/2017, Última modificação: 14/11/2018. Disponível em: https://bit.ly/2Cdzv4d, acesso em: 10/03/2019.

Instituto Brasileiro de Meio Ambiente e dos Recursos Naturais Renováveis

- IBAMA. Nota Técnica no 001/2016 - PRESID/IBAMA Termo de Transação e de Ajustamento de Conduta Relativo ao Rompimento da Barragem do Fundão em Mariana/MG. (2016). Brasília/DF, 29 de fevereiro de 2016. Disponível em: https://bit.ly/2TTipTW, acesso em: 21/03/2019.

BÜHRING, Marcia Andrea. O (des) amparo aos refugiados e aos "novos refugiados": os ambientais. In: ZAVASCKI, Liane Tabarelli et all. (org.) Temas de direito ambiental. Porto Alegre: Editora Fi, 2015, p. 181-218.

GERAQUE, Eduardo; MENA, Fernanda. Tragédia em Minas Gerais deve secar e criar deserto de lama. Folha de São Paulo, Cotidiano, p. B1, B3, 15 nov. 2015. Disponível em: https://bit.ly/1SuwiMO, acesso em 19 jul. 2016.

GONÇALVES, Darly Prado. Principais desastres ambientais no Brasil e no mundo. Jornal da Unicamp, 01 de dezembro de 2017, disponível em https://bit.ly/2qN1dhU, acesso em 10 mar. 2019.

HARARI, Yuval Noah. Sapiens - Uma breve história da humanidade. 30.ed. Trad. Janaína Marcoantonio. Porto Alegre: L\&PM, 2017.

JUBILUT, Liliana Lyra. $O$ direito internacional dos refugiados e sua aplicação no ordenamento jurídico brasileito. São Paulo: Método, 2007. Disponível em https://bit.ly/2u0gltS. Acesso em 10 mar. 2019.

LOPEZ, Aurelie. The protection of environmentally displaced persons in international law. Environmental Law, v. 37, n. 2, p. 365-409, Spring 2007.

MATTAR, Marina Rocchi Martins. Migrações ambientais, direitos humanos e o caso dos pequenos países insulares. Dissertação (Mestrado) - Instituto de Relações Internacionais, Universidade de São Paulo, São Paulo, 2012.

MINAS GERAIS. Tribunal de Justiça de Minas Gerais. $2^{\underline{a}}$ Vara da Comarca de Mariana/MG. Processo no 0400.15.003989-1. Numeração única: 0039891- 
33.2015.8.13.0400. Classe: Cautelar. Requerente: Ministério Público do Estado de Minas Gerais. Requerido: Samarco Mineração S.A. Distribuição: 10/11/2015, disponível em https://bit.ly/2BpKFBv, acesso em 17/12/2018.

ORGANIZAÇÃO DAS NAÇÕES UNIDAS (ONU). Alto Comissariado das Nações Unidas para Refugiados (ACNUR). Refugiados e migrantes: perguntas frequentes. 22 mar. 2016. Disponível em: https://bit.ly/2TAcZfK, acesso em: 10 mar. 2019.

Alto Comissariado das Nações Unidas para Refugiados (ACNUR). Convenção relativa ao Estatuto dos Refugiados (1951), Disponível em: https://bit.ly/2K04bbL, acesso em: 10 mar. 2019.

$\mathrm{OUCHO}$, John O. Environmental impact of refugees and internally displaced persons in Sub-Saharan Africa. Keynote Address to the African Migration Alliance Biennial Workshop on Climate Change, Environment and Migration, East London, South Africa, 15-16 November 2007. Disponível em: https://bit.ly/2Tsrirm, acesso em: 10 mar. 2019.

RAMOS, Érika Pires. Refugiados ambientais: em busca de reconhecimento pelo direito internacional. Tese (doutorado) - Faculdade de Direito da USP, Orientador: Alberto do Amaral Júnior. São Paulo, 2011, disponível em https://bit.ly/2VSp0L3, acessado em 10 mar. 2019.

RODRIGUES, Léo. Reconstrução de distrito destruído na tragédia de Mariana tem avanço. Agência Brasil. Publicado em 16/01/2019, 22:05, disponível em https://bit.ly/2RzCJZf, acesso em 28 mar. 2019.

SCALCO, Patrícia Fernanda. "Refugiados Ambientais" e a Lacuna Jurídica no Direito Internacional Público. Revista Direitos Humanos e Democracia, Programa de PósGraduação Stricto Sensu em Direito da Unijuí, a. 3, n. 5, jan./jun., 2015 (ISSN 23175389) Editora Unijuí.

SOARES, Carina de Oliveira. A efetividade do Direito Internacional dos refugiados no ordenamento jurídico brasileiro. In: CAUBET, Christian G. (coord.) Tratados internacionais, direitos fundamentais, humanos e difusos: os estados contra 0 bem viver de suas populações. São Paulo: Insular, 2016.

SOUZA, Leonardo da Rocha de. Interação social, identidade e pertencimento: fundamentos sociológicos da formação do Direito. In: SOUZA, Leonardo da Rocha de (Org.). Formação humanística em direito. Jundiaí: Paco, 2018, p. 63-79.

SPAREMBERGER Raquel Fabiana; VERGANI, Vanessa. Migração, vulnerabilidade e (in) justiça ambiental: desafios e perpectivas. Revista do Direito UNISC, Santa Cruz do Sul, n. 33, p. 130-147, jan./jun. 2010.

TEIXEIRA, Orci Paulino Bretanha. A fundamentação ética do estado socioambiental. Porto Alegre: Editora Fi, EdiPUCRS, 2013. 